\title{
Cochlear electrophysiology and histopathology of rats exposed to intratympanic silica nanoparticles
}

\author{
Erkan ÖZBAY 1 (D), Ülkü ÇÖMELEKOĞLU 2* (D), Yusuf VAYISOGLU ${ }^{3}(\mathbb{D})$, Önder ALBAYRAK 4 (D), \\ Rabia BOZDOĞAN ARPACI ${ }^{5}$ (D), Burcu DEMİRAĞ ${ }^{6}$ (D), Döndü Anış DENİ ${ }^{3}$ iD, Derya Ümit TALAŞ ${ }^{3}$ (iD)
}

1 Vocational School of Health Service, Karamanoğlu Mehmetbey University, Karaman, Turkey

2 Department of Biophysics, Faculty of Medicine, Mersin University, Mersin, Turkey.

3 Department of Otorhinolaryngology, Faculty of Medicine, Mersin University, Mersin, Turkey

4 Department of Mechanical Engineering, Faculty of Engineering, Mersin University, Mersin, Turkey

5 Department of Pathology, Mersin University, Faculty of Medicine, Mersin, Turkey,

6 Department of Histology and Embryology, Mersin University, Faculty of Medicine, Mersin, Turkey

* Corresponding Author. ulkucomelekoglu@mersin.edu.tr (Ü.Ç.); Tel. +90-324-361 0001.

Received: 01 July 2019 / Revised: 26 August 2019 / Accepted: 13 September 2019

\begin{abstract}
Toxic effects of silica nanoparticle of rats exposed intratympanically for 7 days were investigated using brainstem auditory evoked potential and distortion product otoacoustic emission techniques. The histopathological changes were evaluated with light microscopy and field emission-scanning electron microscopy were demonstrated in cochleas using based energy-dispersive X-ray spectroscopy. The reduction in the amplitude and prolongation at the peak latency and interpeak latencies of brainstem auditory evoked potential were observed. Silica nanoparticles significantly reduced distortion product otoacoustic emission amplitude in the 2,3 and $4 \mathrm{kHz}$ frequencies. In the light microscopic evaluation, the samples obtained from the experimental group showed a significant loss of hair cells. Field emission scanning electron microscope analysis of experimental group showed considerable hair cell damage compared to control group. The findings of this study show that intratympanic administration of silica nanoparticles may lead to hearing impairment by causing structural changes in cochlear hair cells.
\end{abstract}

KEYWORDS: Silica nanoparticle; cochlea; brainstem auditory potential; otoacoustic emission; hair cell; histopathology

\section{INTRODUCTION}

Amorphous silica nanoparticles $\left(\mathrm{SiO}_{2} \mathrm{NPs}\right)$ are considered a promising candidate for a variety of biomedical applications, such as gene delivery, drug delivery and molecular imaging [1]. Previous studies have shown that exposure of $\mathrm{SiO}_{2} \mathrm{NPs}$ cause genotoxicity [2], cardiotoxicity [3], increased oxidative stress, cytotoxicity [4, 5, 6], macrophage activation [7], apoptosis [8], autophagy [9], morphological changes in various tissues [10], an increase in blood cell count and organ damage biomarkers [11], and inflammation [12].

Hearing loss is one of the most common symptoms on the world. Sensorineural hearing loss (SNHL) accounts for about $90 \%$ of all hearing losses and over $5 \%$ is disabling [13]. Since nanoparticles can carry various drugs, proteins and nucleic acids into the inner ear, it exhibits new possibilities in the treatment of SNHL [14]. The liposomes/lipoplexes, lipidic nanocapsules, chitosan nanoparticles, amorphous silica nanoparticles, polymeric nanoparticles, nanogels are the most commonly used nanoparticles in the treatment of SNHL [14].

In recent years, rather than studies investigating the toxic effects of nanoparticles on the inner ear, researchs have been focused on the transmission of a drug and gene on to the nanoparticle to the inner ear and to observe of the functional changes it produces. There is a limited number of studies that investigated effects of $\mathrm{SiO}_{2}$ nanoparticle on rat cochlea $[15,16]$. Therefore, the present study aimed to investigate the toxic effects of $\mathrm{SiO}_{2}$ nanoparticle on rat cochlea. In this study, rats were used due to cochlear similarity to human beings $[17,18]$. The distribution of $\mathrm{SiO}_{2} \mathrm{NPs}$ in the rat cochlea after intratympanic injection was demonstrated by using Field Emission Scanning Electron Microscopes (FE-SEM) based energy-dispersive X-ray spectroscopy (EDX). The effects of $\mathrm{SiO}_{2} \mathrm{NPs}$ on functional changes in the cochlea were investigated using Brain Stem Auditory Evoked Potential (BAEP) and Distortion Product Otoacoustic Emission (DPOE) recording techniques. Finally, the histopathological changes of $\mathrm{SiO}_{2} \mathrm{NPs}$-induced in the cochlea were evaluated with light microscopy and FE-SEM.

How to cite this article: Özbay E, Cömelekoğlu U, Vayısoglu Y, Albayrak Ö, Bozdoğan Apacı R, Demirbağ B, Deniz DA, Talas DÜ. Cochlear electrophysiology and histopathology of rats exposed to intratympanic silica nanoparticles. J Res Pharm. 2019; 23(6): 1115-1122. 


\section{RESULTS}

\subsection{Nanoparticle characterization}

The physical-chemical characteristics of $\mathrm{SiO}_{2}$ nanoparticles were determined with multiple methods. Structural properties of the silica nanoparticles were investigated by FE-SEM studies. FE-SEM imaging of the nanoparticles showed uniform spherical structures with size of $20.54 \pm 2.23 \mathrm{~nm}$. This result is also confirmed by DLS measurement $(20.42 \pm 1.71)$. All the samples were shown strong broad peak at about $2 \theta=22^{\circ}$. This peak confirms the amorphous phase of silica nanoparticles.

\subsection{Brainstem auditory evoked potential}

BAEP is a physiological measure of the brainstem's response to sound and tests the integrity of the hearing system from the ear to the brainstem. Amplitudes and PLs of I-V waves and IPLs were measured from BAEP records. Amplitudes of the first and third waves in the experimental group significantly decreased compared to the control group $(\mathrm{p}<0.05)$ (Table 1). In the experimental group, PLs of the first and third waves were found to be longer than the control group $(\mathrm{p}<0.05)$ (Table 1). Additionally, IPL of I-III waves in the experimental group were significantly longer than the control group $(\mathrm{p}<0.05)($ Table 1$)$.

Table 1. BAEP amplitudes, peak latencies and interpeak latencies in control $(n=6)$ and experimental $(n=6)$ groups at different frequencies. All data were presented as mean \pm standart deviation.

\begin{tabular}{llccc}
\hline Variables & Waves & Control & Experiment & $\mathrm{p}^{*}$ \\
\hline Amplitude $(\mu \mathrm{V})$ & Wave I & $1.17 \pm 0.48$ & $0.77 \pm 0.18$ & 0.124 \\
& Wave III & $0.98 \pm 0.22$ & $0.34 \pm 0.07$ & 0.001 \\
& Wave V & $0.062 \pm 0.02$ & $0.06 \pm 0.02$ & 0.789 \\
Peak Latency $(\mathrm{ms})$ & Wave I & $1.29 \pm 0.32$ & $1.59 \pm 0.16$ & 0.105 \\
& Wave III & $3.01 \pm 0.34$ & $3.75 \pm 0.77$ & 0.041 \\
İnterpeak Latency $(\mathrm{ms})$ & Wave V & $5.13 \pm 0.44$ & $5.99 \pm 1.20$ & 0.173 \\
& Waves I-III & $1.45 \pm 0.082$ & $2.18 \pm 0.62$ & 0.033 \\
& Waves I-V & $3.62 \pm 0.65$ & $4.39 \pm 0.89$ & 0.160 \\
& Waves III-V & $2.18 \pm 0.65$ & $2.27 \pm 0.38$ & 0.795 \\
\hline
\end{tabular}

${ }^{*} \mathrm{p}$ values less than 0.05 were considered as statistically significant.

\subsection{Distortion product evoked otoacoustic emission}

Table 2 shows DPOAE amplitudes as a function of $\mathrm{f} 2$ frequency for control and experimental groups. There was a significant reduction in DPOAE amplitude in the 2,3 and $4 \mathrm{kHz}$ frequencies between control and experimental groups $(\mathrm{p}<0.05)$. Such reduction was not seen in the other tested frequencies $(6 \mathrm{and} 8 \mathrm{kHz})$.

Table 2. DPOAE values in control $(n=6)$ and experimental $(n=6)$ groups at different frequencies. All data were presented as mean \pm standart deviation.

\begin{tabular}{cccc}
\hline DPOAE frequencies $\mathbf{( H z )}$ & Control & Experiment & $\mathbf{p}^{*}$ \\
\hline 2 & $6.67 \pm 2.32$ & $3.50 \pm 1.15$ & 0.013 \\
3 & $13.58 \pm 4.16$ & $10.20 \pm 3.08$ & 0.048 \\
4 & $21.65 \pm 2.95$ & $15.18 \pm 5.84$ & 0.023 \\
6 & $21.17 \pm 4.16$ & $22.64 \pm 7.11$ & 0.645 \\
8 & $21.31 \pm 6.51$ & $20.24 \pm 9.57$ & 0.811 \\
\hline
\end{tabular}

${ }^{*} \mathbf{p}$ values less than 0.05 were considered as statistically significant.

\section{4. $\mathrm{SiO}_{2}$ nanoparticles in cochlea: FE-SEM-EDX analysis}

The presence of $\mathrm{SiO}_{2}$ nanoparticles was determined in the cochlea by using FE-SEM based EDX analysis. Samples of EDX records for control (Figure 1A) and experimental groups (Figure 1B) were shown in Figure 1. In the control group, this spectrum shows six elements which were identified as carbon, platinum, palladium, nitrogen, oxygen and sodium. In the experimental group, this spectrum contains carbon, platinum, palladium, 
nitrogen, oxygen, sodium and silicon elements. As can be seen from these spectra, the samples in the experimental group contain silica element unlike the control group.
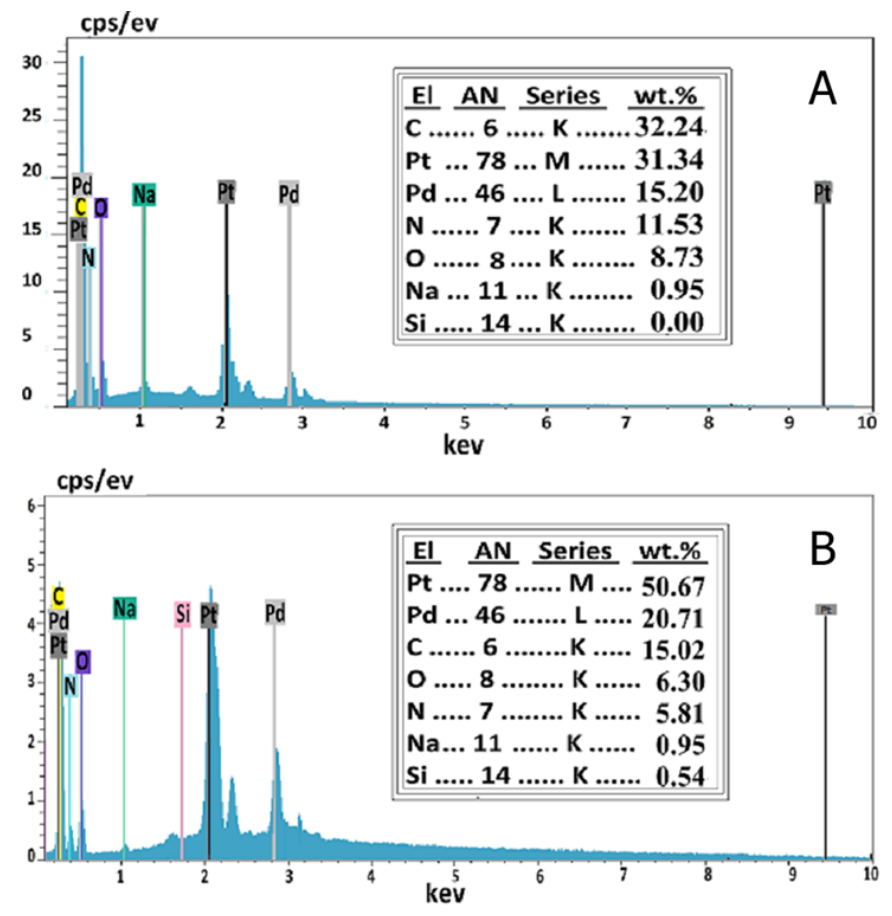

Figure 1. EDX spectrum analysis of cochlea for control (A) and experimental group (B).

\subsection{Light microscopic findings}

Spiral ganglion cells and nerve tissue were in normal appearance both in the control and experimental groups. The samples obtained from the $\mathrm{SiO}_{2}$ exposed group showed a significant hair cell loss (Figure 2A, 2B, $2 \mathrm{C}$ and 2D). Mean numbers of hair cell were 51.7 \pm 2.5 and $29.3 \pm 5.85$ in control and experimental groups, respectively. In the number of hair cells, there was a significant difference between control and experimental groups ( $\mathrm{p}=0.012$ ). The percent of hair cells loss was calculated as $43.3 \%$ in the experimental group.
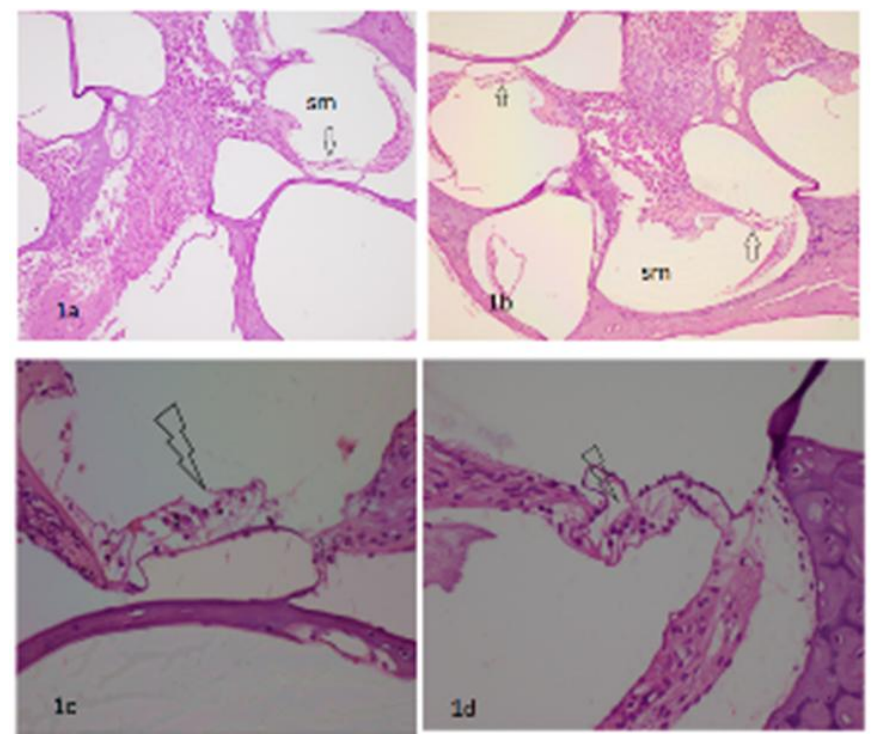

Figure 2. Histological sections show cochlea tissue in rats: Arrows show hair cells in the scala media (sm) for the experimental group (1a) and for the control group (1b) (H-E, x200). Arrowheads show an average of 9-12 viable hair cells in the experimental group (1c) and 15-18 hair cells in the control group (1d) (H-E, x400). 


\subsection{FE-SEM findings}

In the control group, the V-shaped stereociliary tufts and bending of stereocilia were observed (Figure 3A). In the experimental group, disrupted morphology of the V-shaped stereociliary tufts and stereociliary degeneration involving shortening and disappearance were observed (Figure 3B and Figure 3C).
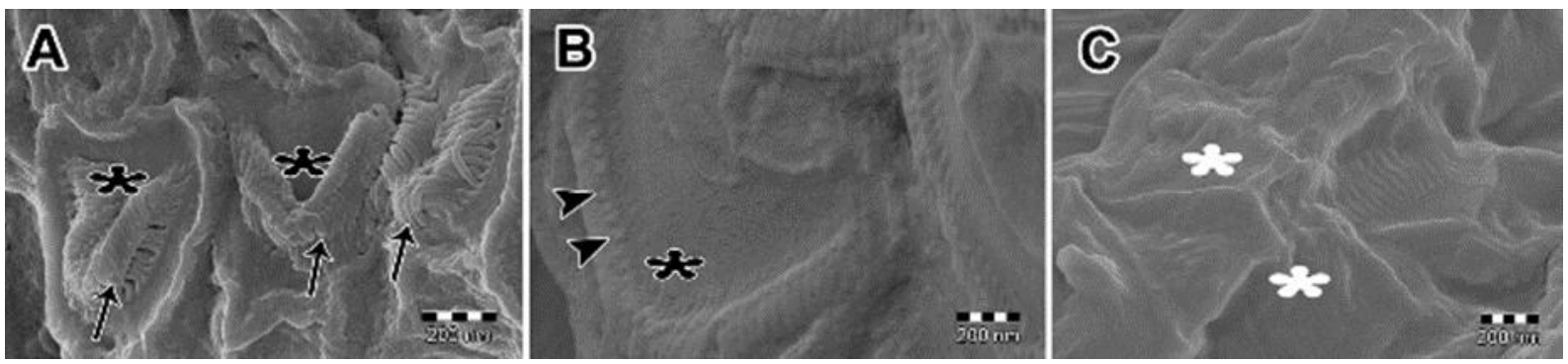

Figure 3. FE-SEM of the outer hair cells. A. The V-shaped stereociliary tufts (black asterisks), bending of stereocilia (arrows) are seen in the control group. B. The V-shaped stereociliary tufts (black asterisk) and stereociliary degeneration involving shortening (arrowheads) are seen in the experimental group. C. Morphology of the V-shaped stereociliary tufts (white asterisks) are disrupted and stereociliary degeneration involving shortening and disappearance is seen in the experimental group.

\section{DISCUSSION}

In this study, the effects of $\mathrm{SiO}_{2} \mathrm{NPs}$ on cochlear activity and morphology were investigated by using biophysical and histopathological methods. Findings from the present study indicated that $\mathrm{SiO}_{2} \mathrm{NPs}_{\mathrm{s}}$ caused significant functional and structural changes in the rat cochlea.

There are a number of electrophysiological parameters that can be monitored to assess cochlear function including DPOAE and BAEP. In the present study, both BAEP and DPOAE were recorded to monitor the cochlear function. Significantly reduced amplitudes (first and third waves), prolonged peak latencies (first and third wave) and interpeak latencies (first-third waves) were observed in BAEP recordings. The reduction in the mean amplitudes of first wave and third wave were $34.1 \%$ and $63 \%$, respectively. The prolongation of the peak latency of the first wave was $24.58 \%$ and third wave was $24.5 \%$. The prolongation of interpeak latency of the first-third waves was $49.3 \%$. Identification of the generators of the BAEP waveforms is primarily based on studies in humans and animals. The first positive waveform (I) is generated by the vestibulocochlear nerve or spiral ganglion cells of the cochlea, the third peak (III) by cells of the cochlear nuclei and dorsal olivary complex and fifth (V) peak by neurons in dorsal olivary complex, lateral lemniscus, and caudal colliculus [19]. The significantly longer latencies for interwave intervals I-III in the experimental group may be related to the delayed central conduction time of neural transmission through the brainstem. Another important finding in this study is the decrease of first and third waves BAEP amplitudes. A decreased amplitude can be regarded as a sign of a decreased synchronism of the burst of sensory impulses [20]. In the present study, at 2, 3 and 4 $\mathrm{kHz}$ frequencies, the DPOAE amplitudes of experimental rats reduced $47.5 \%, 24.8 \%$ and $29.8 \%$, respectively when compared to control group. This result suggests that mid-low-frequency region $(2-4 \mathrm{kHz})$ may be affected by $\mathrm{SiO}_{2} \mathrm{NPs}$ in the experimental rats. DPOAE reflects outer hair cell integrity and cochlear function [21]. The hair cells convert sound into electrical signals and loss of hair cells lead to hearing loss. Histological analysis was consistent with electrophysiological data regarding a broad loss of hair cells occurred mainly in middle-apical turn of the cochlea in our experimental group. There is a limited number of studies in the literature that examine the effects of $\mathrm{SiO}_{2} \mathrm{NPs}$ on the hearing system. A pilot study in mice tested the influence of diffusion of Cy3-labeled $\mathrm{SiO}_{2} \mathrm{NP}$ applied near the round window membrane and these NPs were demonstrated inside the inner hair cells, the vestibular hair cells, the spiral ganglion neurons and the supporting cells, without any hearing loss or inflammation. Therefore, the authors concluded that $\mathrm{SiO}_{2} \mathrm{NPs}_{\mathrm{S}}$ could be applied for safe drug delivery in the auditory system [15]. In another study in which $\mathrm{SiO}_{2} \mathrm{NPs}(7$ $\mathrm{mg} / \mathrm{kg}$ ) was administered intravenously, DPOAE values were recorded at baseline and on days 21 and 60 after treatment and it was observed that DPOAE amplitude remained unchanged after administration of NPs [16]. The findings of our study are not concordant with above mentioned investigations. In our study, the damage caused by $\mathrm{SiO}_{2} \mathrm{NPs}$ in the hair cells was clearly seen in histopathological examinations as well as electrophysiological data. In both studies, $\mathrm{SiO}_{2} \mathrm{NPs}$ were administered in a single dose. Although the total 
administered doses of Ivanov's (2012) and our studies seem to be nearly equal, the main difference is the number of applications.

Repeated applications (7 consecutive days; totally $1.75 \mathrm{mg}$ ) in our study may be the reason for histological deterioration and loss of hearing. Repeated applications of $\mathrm{SiO}_{2} \mathrm{NPs}$ may lead to greater nanoparticle deposition in the cochlea and damage of the hair cells compared to single administration regardless of dose [22, 23].

\section{CONCLUSION}

In conclusion, the findings of this study show that intratympanic administration of $\mathrm{SiO}_{2} \mathrm{NPs}_{\mathrm{s}}$ may lead to hearing impairment by causing structural changes in cochlear hair cells. In the light of these findings, nanobased therapy technology needs to be thoroughly investigated. The probable underlying mechanisms of action through biochemical, ultrastructural, electrophysiological, molecular and histological means are to be studied for toxicity to overcome any undesired effects before clinical use.

\section{MATERIALS AND METHODS}

\subsection{Chemicals}

$\mathrm{SiO}_{2} \mathrm{NPs}$ were purchased from Sigma-Aldrich (S Louis, MO, USA). According to the manufacture's data sheet, the properties are as follows: $99.5 \%$ trace metals basis nanopowder (spherical, porous), surface area 590$690 \mathrm{~m}^{2} / \mathrm{g}$. All other chemicals were purchased from Polar Ltd. (Adana, Turkey).

\subsection{Nanoparticle characterization}

Nanopowder $\mathrm{SiO}_{2}(0.15 \mathrm{~g})$ suspended in $30 \mathrm{~mL}$ physiological saline solution by magnetic blender (IKA®) C-MAG HS 7, Staufen, Germany) for 15 minutes and dispersed in saline solution by ultra-sonication for 30 minutes (Model HD 2200, Bandelin Electronics, Berlin, Germany). X-ray Powder Diffraction (XRD) measurements were carried out (D8 Advance, Bruker, Karlsruhe, Germany) and FE-SEM images were obtained (Supra 55, Carl Zeiss, Jena, Germany) for samples platinum coated prior to the measurements. The shape and size of particles were verified by FE-SEM and dynamic light scattering (DLS) (Zetasizer Nano ZS, Malvern Panalytical, Malvern, UK).

\subsection{Animals and experimental design}

Twelve adult Wistar albino male rats weighing 200-250 g were obtained from the Experimental Animal Center of Mersin University (Mersin, Turkey) and divided into control $(n=6)$ and experimental $(n=6)$ groups. The animals were housed in polycarbonate cages, ( 6 rats per cage), at $25 \pm 1.5^{\circ} \mathrm{C}$ and $55 \%$ humidity under the 12:12 h day-night cycle and fed with standard pellet (MBD Animal Feed Trading Company, Kocaeli, Istanbul) and water provided ad libitum. The experimental protocol was approved by Mersin University Experimental Animals Local Ethics Committee and carried out in accordance with the National Institutes of Health's Guide for the Care and Use of Laboratory Animals.

\section{4. $\mathrm{SiO}_{2}$ exposure}

All rats were anesthetized using $90 \mathrm{mg} / \mathrm{kg}$ ketamine, and $7 \mathrm{mg} / \mathrm{kg}$ xylazine. External auditory canals and tympanic membranes were examined by using surgical microscope and ear speculum. The rats were exposed to intratympanic injection of $250 \mu \mathrm{g} /$ day $\mathrm{SiO}_{2} \mathrm{NPs}$ suspension under a surgical microscope for 7 consecutive days. Left ear was used for intratimpanic injection in all rats. The control rats were injected with $0.9 \%$ saline. At the end of the 7 th day, the rats were otologically examined again.

\subsection{Brain auditory evoked potential (BAEP) recordings}

BAEPs were recorded 5 days after the last injection from the control and experimental groups. The BAEP records were obtained by anesthetizing the rat using ketamine-xylazine. Three subcutaneous needle electrodes placed at the vertex (reference electrode), the mastoid ipsilateral to the stimulated ear (active electrode) and abdominal region (ground electrode). Responses were averaged 1000 times. Less than $5 \mathrm{k} \Omega$ for each electrode was accepted as appropriate for impedance measurements. BAEP data were collected using a Nicolet Endeavorsystem (MFI Medical, San Diego, CA, USA). The biological signal was bandpass filtered (0.15-3.0 $\mathrm{kHz}$ ) and amplified with the artefact rejection level (set at $10 \mu \mathrm{V}$ ). Click stimulus with $4.1 \mathrm{~Hz}$ frequency, 200 $\mu$ s duration and $20 \mathrm{~mA}$ intensity $(90 \mathrm{~dB})$ were used for BAEP records. A noise of $50 \mathrm{~dB}$ was applied to the 
unrecorded ear. The BAEP peak latencies (PLs), interpeak latencies (IPLs) and amplitudes were measured from recordings. Latency was measured from the end of the stimulus to the time of the corresponding peak. Each amplitude was measured as the voltage difference between the baseline and the corresponding peak.

\subsection{Distortion product evoked otoacoustic emission (DPOAE) recordings}

DPOAEs were recorded by the MADSEN Capella-GN Otometrics Otoacoustic Emissions device (Taastrup, Denmark) in an insulated room. The rats were anesthetized and a probe was coupled to their right external auditory canal (probes used in newborn babies). The stimulus was made up of 2 pure sounds (f1 and $\mathrm{f} 2$ ), which $\mathrm{f1} / \mathrm{f} 2$ frequency ratio was 1.22. Stimuli intensity was fixed in $65 \mathrm{~dB}$ SPL. The resulting otoacoustic emissions were assessed in the frequencies of 2, 3, 4, 6 and $8 \mathrm{kHz}$.

\subsection{Animal preparation and pre-fixation}

After the record of DPOAE, intracardially mixture of $4 \%$ paraformaldehyde and $0.5 \%$ gluteraldehyde was perfused to rats under general anesthesia. Following perfusion, cochleas were isolated (Albuquerque et al. 2009) and kept in paraformaldehyde for 3 days. After fixation, the cochleas were transferred to test tubes containing 10\% disodium EDTA (Ethylenediaminetetraacetic acid) solution for decalcification and they were kept in this solution for 14 days [24]. Before going to next step, cochleas were checked whether they were very well decalcified. A very well decalcification is considered when the cochleae became soft at touch with forceps.

\subsection{Light microscopic evaluation}

Following the decalcification, the cochleas were prepared for histopathological examination. Samples were fixed with $10 \%$ formalin for 24 hours at $4{ }^{\circ} \mathrm{C}$. Afterward, tissues were dehydrated in a graded series of alcohols, cleared in xylene and embedded in paraffin. The paraffin blocks were cut into $4 \mu \mathrm{m}$ thick slices and the slices were stained with hematoxylin-eosin. Hematoxylin and eosin stained sections from each specimen were examined under light microscope (Olympus BX50, Tokyo, Japan). The presence of outer hair cells was assessed in each cochlear turn. To calculate the percent of cochlear hair cell loss, the cells in the three scala media were counted in control and experimental group. The percent of loss of hair cells was calculated from the following equation (Eq. 1):

Percent of hair cell loss $=\left[\left(\mathrm{N}_{\mathrm{c}}-\mathrm{N}_{\mathrm{e}}\right) / \mathrm{N}_{\mathrm{c}}\right]^{*} 100$

where $N_{c}$ is the number of hair cells in control group and $N_{e}$ is number of hair cells in experimental group.

\subsection{FE-SEM microscopy}

Following decalcification, cochleas were carefully cleaned of surrounding muscle tissue under an Olympus SZX9 stereomicroscope, washed in phosphate saline ( $\mathrm{pH} 7.4$ ) and dehydrated in graded ethanol series and critical-point dried using a critical point dryer (Emitech K850, Quorum, England). Samples were coated in palladium-platinum in a sputter coating system (Quorum150, England). Sputter coating is the standard method for preparing non-conducting or poorly conducting specimens prior to observation in a scanning electron microscope. Palladium-platinum coated samples were placed on the aluminium stubs for FE-SEM device by using stereomicroscope (Model SZX2-ILLB, Olympus Cor. Tokyo, Japan) and were investigated under FE-SEM (Zeiss, Supra 55, Germany).

\subsection{Confirmation of cochlear $\mathrm{SiO}_{2}$ with FE-SEM-EDX analysis}

EDX analysis is a technique used for identification of the elemental composition and distribution of a specimen. Scanning electron microscopy based energy dispersive X-ray spectroscopy (FE-SEM-EDX) was used to confirm the presence of cochlear $\mathrm{SiO}_{2}$ nanoparticles. EDX measurements were performed on a Compact Detector Unit incorporated into a Zeiss, Supra 55 FE-SEM. The EDX spectrum was obtained at an acceleration voltage of $10 \mathrm{kV}$.

\subsection{Statistical analysis}

Data were analyzed using SPSS 17.0 statistical package program (SPSS v.11.5, SPSS Inc., Chicago IL, USA). The checks of normality of variables were tested with Kolmogorov-Smirnov test. Descriptive statistics of variables were expressed as mean and standard deviation. Student t-test was used to compare control and experimental groups for normal distribution variables. $\mathrm{p}$ values less than 0.05 were considered as statistically significant. 
Acknowledgements: This study was supported by the Research Fund of Mersin University in Turkey with Project Number: BAP- 2017-1-TP2-2143.

Author contributions: Concept - E.Ö., Ü.Ç.; Design - E.Ö., Ü.Ç., D.Ü.T.; Supervision - E.Ö., Ü.Ç.; Materials - E.Ö, Ü.Ç.; Data Collection and/or Processing - E.Ö., Ü.Ç., D.Ü.T, Y.V., Ö. A., D.A.D., R. B. A., B.D.; Analysis and/or Interpretation - E.Ö., Ü.Ç., D.Ü.T, Y.V., Ö. A., D.A.D., R.B.A., B.D.; Literature Search - E.Ö., Ü.Ç., DÜ.T, Y.V., Ö. A., D.A.D., R.B.A., B.D.; Writing - E.Ö., Ü.Ç., DÜ.T, Y.V., Ö.A., D.A.D., R.B.A., B.D.; Critical Reviews - Ü.Ç., E.Ö., D.Ü.T., Y.V., Ö.A., R.B.A., D.A.D., B.D.

Conflict of interest statement: The authors declared no conflict of interest.

\section{REFERENCES}

[1] Murugadoss S, Lison D, Godderis L, Van Den Brule S, Mast J, Brassinne F, Sebaihi N, Hoet PH. Toxicology of silica nanoparticles: an update. ArchToxicol. 2017; 91(9): 2967-3010. [CrossRef]

[2] Maser E, Schulz M, Sauer UG, Wiemann M, Ma-Hock L, Wohlleben W, Hartwig A, Landsiedel R. In vitro and in vivo genotoxicity investigations of differently sized amorphous $\mathrm{SiO}_{2}$ nanomaterials. Mutat Res Genet Toxicol Environ Mutagen. 2015; 794: 57-74. [CrossRef]

[3] Du Z, Zhao D, Jing L, Cui G, Jin M, Li Y, Xiaomei L Ying L, Haiying D, Caixia G, Xianging Z, Zhiewi S. Cardiovascular toxicity of different sizes amorphous silica nanoparticles in rats after intratracheal instillation. Cardiovasc Toxicol. 2013; 13(3): 194-207. [CrossRef]

[4] Shrivastava, R, Raza S, Yadav A, Kushwaha P, Flora SJ. Effects of sub-acute exposure to $\mathrm{TiO}_{2}, \mathrm{ZnO}$ and $\mathrm{Al}_{2} \mathrm{O}_{3}$ nanoparticles on oxidative stress and histological changes in mouse liver and brain. Drug and Chem Toxicol. 2014; 37(3): 336-347. [CrossRef]

[5] Duan, J, Yu Y, Li Y, li Y, Liu H, Jing L, Yang M, Jing L, Yang M, Wang J, Chunqi L, Zhiewi S. Low dose exposure of silica nanoparticles induces cardiac dysfunction via neutrophil mediated inflammation and cardiac contraction in zebrafish embryos. Nanotoxicology. 2016; 10(5): 575-585. [CrossRef]

[6] Breznan D, Das DD, O'Brien JS, MacKinnon-Roy C, Nimesh S, Vuong NQ, Bernatchez S, De Silva N, Hill M, Kumarathasan P, Vincent R. Differential cytotoxic and inflammatory potency of amorphous silicon dioxide nanoparticles of similar size in multiple cell lines. Nanotoxicology. 2017; 11(2): 223-235. [CrossRef]

[7] Yang, M, Jing L, Wang J, Yu Y, Cao L, Zhang L, Zhou X, Sun Z. Macrophages participate in local and systemic inflammation induced by amorphous silica nanoparticles through intratracheal instillation. Int J Nanomedicine. 2016; 11: 6217-6228. [CrossRef]

[8] Tarantini A, Lanceleur R, Mourot A, Lavault MT, Casterou G, Hogeveen K, Fessard V. Toxicity, genotoxicity and proinflammatory effects of amorphous nanosilica in the human intestinal Caco-2 cell line. Toxicol in Vitro. 2015b; 29(2): 398- 407. [CrossRef]

[9] Guo C, Yang M, Jing L, Wang J, Yu Y, Li Y, Duan J, Zhou X, Li Y, Sun Z. Amorphous silica nanoparticles trigger vascular endothelial cell injury through apoptosis and autophagy via reactive oxygen species-mediated MAPK/Bcl2 and PI3K/Akt/mTOR signalling. Int J Nanomedicine. 2016; 11: 5257-5276. [CrossRef]

[10] Yu Y, Li Y, Wang W, Jin M, Du Z, Li Y, Duan J. Yu Y, Sun Z. Acute toxicity of amorphous silica nanoparticles in intravenously exposed ICR mice. PloS one. 2013; 8(4): e61346. [CrossRef]

[11] Nemmar A, Yuvaraju P, Beegam S, Yasin J, Kazzam EE, Ali BH. Oxidative stress, inflammation, and DNA damage in multiple organs of mice acutely exposed to amorphous silica nanoparticles. Int J Nanomedicine. 2016; 11: 919-28. [CrossRef]

[12] Di Cristo L, Movia D, Bianchi MG, Allegri M, Mohamed BM, Bell AP, Moore C. Pinelli S, Rasmussen K, Sintes JR, Mello AP, Bussaloti O, Bergamaschi E. Proinflammatory effects of pyrogenic and precipitated amorphous silica nanoparticles in innate immunity cells. Toxicol Sci. 2015; 150(1): 40-53. [CrossRef]

[13] Li L, Chao T, Brant J, O'Malley B, Tsourkas Jr A, Li D. Advances in nano-based inner ear delivery systems for the treatment of sensorineural hearing loss. Adv Drug Deliv Rev. 2017; 108: 2-12. [CrossRef]

[14] Pyykkö I, Zou J, Schrott-Fischer A, Glueckert R, Kinnunen P. An overview of nanoparticle based delivery for treatment of inner ear disorders. In Sokolowski B (Ed). Auditory and Vestibular Research. Humana Press, New York, 2016, pp. 363-415.

[15] Praetorius M, Brunner C, Lehnert B, Klingmann C, Schmidt H, Staecker H, Schick B. Transsynaptic delivery of nanoparticles to the central auditory nervous system. Acta Otolaryngol, 2007; 127(5): 486-490. [CrossRef] 
[16] Ivanov S, Zhuravsky S, Yukina G, Tomson V, Korolev D, Galagudza M. In vivo toxicity of intravenously administered silica and silicon nanoparticles. Materials 2012; 5(10): 1873-1889. [CrossRef]

[17] Kelly JB, Masterton B. Auditory sensitivity of the albino rat. J Comp Physiol Psychol. 1977; 91(4): 930-936.

[18] Albuquerque AAS, Rossato M, de Oliveira JAA, Hyppolito MA. Understanding the anatomy of ears from guinea pigs and rats and its use in basic otologic research. Brazi J Otorhinolaryngo. 2009; 75(1): 43-49.

[19] Celesia GG. Brainstem auditory evoked responses. In: Celesia GG. (Ed). Disorders of peripheral and central auditory processing. Elsevier Health Sciences Netherlands, 2013. pp. 137-154.

[20] Rozhkov VP, Soroko SI. Age-and sex-related differences in brainstem auditory evoked potentials in secondary school students living in Northern European Russia. Hum Physiol. 2009; 35(6): 703-713.

[21] Abdala C, Visser-Dumont L. Distortion product otoacoustic emissions: A tool for hearing assessment and scientific study. Volta Rev. 2001; 103(4): 281-302.

[22] Nishimori H, Kondoh M, Isoda K, Tsunoda S, Tsutsumi Y, Yagi K. Silica nanoparticles as hepatotoxicants. Eur J Pharm Biopharm. 2009; 72(3): 496-501. [CrossRef]

[23] Simonin M, Martins JM, Uzu G, Vince E, Richaume A. Combined study of titanium dioxide nanoparticle transport and toxicity on microbial nitrifying communities under single and repeated exposures in soil columns. Environ Sci Technol. 2016; 50(19): 10693-10699. [CrossRef]

[24] Montgomery SC, Cox BC. Whole mount dissection and immunofluorescence of the adult mouse cochlea. J Vis Exp. 2016; 107: e(53561).

This is an open access article which is publicly available on our journal's website under Institutional Repository at http://dspace.marmara.edu.tr. 